\title{
SHIELDING PROPERTIES OF 316 STAINLESS STEEL WITH MULTI-LAYERED BARRIERS FOR SPENT FUEL DRYCASKS
}

\section{ZEINAB Y. ALSMADI* \& MOHAMED A. BOURHAM}

Department of Nuclear Engineering, North Carolina State University, Raleigh

\begin{abstract}
The shielding properties of 316 stainless steel with multi-layered coatings as barriers for application in spent fuel drycasks are investigated experimentally using gamma-ray sources and computationally using MicroShield Package. The concept of the cask consists of an inner 316 stainless steel canister coated with multi-layer ceramics and glassbased materials then surrounded with an outer shielding concrete overpack. The highest linear attenuation coefficient is observed computationally at $0.302 \mathrm{MeV}$ for $\mathrm{ZrO}_{2}+\mathrm{TiO}_{2}$ double coating layers while the lowest linear attenuation is observed experimentally at $1.332 \mathrm{MeV}$ for $\mathrm{Al}_{2} \mathrm{O}_{3}$ single coating layer. Two concrete forms named $\mathrm{CN}$ and $\mathrm{CZ}$. The highest measured attenuation coefficient occurs for $\mathrm{CZ}$ concrete overpack at $0.356 \mathrm{MeV}$ while the lowest attenuation occurs for CN concrete overpack at $1.332 \mathrm{MeV}$.

KEYWORDS: Gamma Radiation, Shielding Properties, Drycask, Concrete, Glass-Based Coatings \& Attenuation Coefficients
\end{abstract}

Received: Feb 06, 2021; Accepted: Feb 26, 2021; Published: Mar 10, 2021; Paper Id.: IJPRJUN20212

\section{INTRODUCTION}

Radiation dosimetry has become one of the most important fields in physics with the development of technology due to the extensive use of radioactive sources in many applications like nuclear, medical and industry applications. Because radiation can impose risks to health and environment, three main methods should be employed in the process of radiation protection; distance, time and shielding. It is essential to minimize the exposure to ionizing radiation by providing adequate shielding against gamma-rays in which it occurs during the interaction of gamma with matter and depends on the atomic number and density of elements in the shielding material, the energy of the incident gamma and the thickness of the shielding material [1,2]. The mechanism of which gamma radiation interacts with material has three processes; Photoelectric effect, Compton scattering and Pair production. In Photoelectric effect, gamma-rays interact with the atom and transfer all of its energy to an electron causing it to eject from the atom while in Compton scattering, only a portion of the energy of gamma-rays is transferred to an electron in the atom. However, Pair production is less common than the Photoelectric effect or Compton scattering and it occurs only for very high-energy gamma-rays [1,2].

Shielding materials for gamma radiation should have high density and high atomic number in order to have high attenuation coefficients and high photoelectric absorption probability. Shielding materials can be formed in many forms such as high-density concrete, lead bricks, steel plates and cooling pools filled with water [2]. Comparing the thicknesses of different materials to establish the shielding requirements for a particular application along with other factors such as cost, weight, and chemical and physical durability, will allow the choice of the most appropriate type of shielding material for that kind of the desired application [2]. 
In nuclear energy power generation units, drycasks are used to store the spent fuel. They have an inner stainless steel canister and surrounded with a concrete overpack. However, in this research, the concept is to coat the outer of the canister with a thin layer or a multi-layer of glass-based material or ceramics as barriers for diffusion, corrosion and development of micro cracks. The shielding materials of drycasks should be developed continuously in order to provide safety, shielding, physical protection and heat removal [1, 3-6]. The spent fuel drycask canisters are usually composed of austenitic stainless steels because of their high-temperature strength, corrosion-resistance, economic feasibility and good creep-fatigue properties. They are also alloyed with different elements like Chromium $(\mathrm{Cr})$ and Nickel $(\mathrm{Ni})$ to enhance their mechanical properties at different loading conditions [1, 7-9].

Glass-based materials are widely proposed as coatings on drycask stainless steel canisters due to their corrosion resistance, hardness and ease of production, as well as their transparency to visible light when used in x-ray and hot cells viewing windows $[1,10-15]$. On the other hand, the most common shielding material is concrete which is proven to be efficient in many applications, particularly in structural and shielding applications with low cost, high values of linear and mass attenuation coefficients for gamma-rays and neutrons. Several researches investigated the drycask formation [16], and possible improvements in the design of spent fuel storages [17]. Adding high density and high atomic number components as aggregates in concrete can increase its shielding effectiveness, which is important for spent nuclear fuel storage and transportation $[1,3,10-15]$.

This paper investigates the shielding properties of 316 stainless steel with multi-layered coatings of glass-based and ceramics serving as barriers. The investigation was conducted experimentally and computationally using various gamma-ray sources covering photon energies from $0.302 \mathrm{MeV}$ to $1.332 \mathrm{MeV}$. The outer overpack is a specialized blend of concrete marked as $\mathrm{CN}$ and $\mathrm{CZ}$ samples.

\section{MATERIALS AND METHODS}

\subsection{Materials}

The geometry of the drycask proposed in this research consists of an inner 316 stainless steel canister with the outer surface coated with multi-layer glass-based and ceramics materials and encapsulated inside an outer concrete overpack serving as the drycask outer shielding layer from the multi-layered coating concept [4-6] as illustrated in Figure. 1. The multi-layer coatings are added to the surface of the stainless steel canister to provide barriers of specific functionality that protects the canister from corrosion and cracking, and hence extends its lifetime and the entire drycask integrity and survivability. The multi coatings concept has three layers acting as barriers, a TiN diffusion barrier layer followed by a corrosion resistant layer from blended oxides $\left(\mathrm{ZrO}_{2} / \mathrm{TiO}_{2} / \mathrm{Al}_{2} \mathrm{O}_{3}\right)$, and a final coating of $\mathrm{MoS}_{2}$ as a tribology anti-cracking barrier. The blended oxides $\left(\mathrm{ZrO}_{2} / \mathrm{TiO}_{2} / \mathrm{Al}_{2} \mathrm{O}_{3}\right)$ are similar to the composition of zirconolite $\left(\mathrm{CaZrTi}_{2} \mathrm{O}_{7}\right)$, where the composition of the zirconolite has $33.86 \% \mathrm{ZrO}_{2}, 32.03 \% \mathrm{TiO}_{2}$ and $1.40 \% \mathrm{Al}_{2} \mathrm{O}_{3}$, with $12.33 \% \mathrm{CaO}$. The calcium oxide replaced by increased percentage of aluminum oxide formulates the blended oxide zirconia titania alumina $\left(\mathrm{ZrO}_{2} / \mathrm{TiO}_{2} / \mathrm{Al}_{2} \mathrm{O}_{3}\right)$ for the corrosion-resistance layer of the middle coating on the canister.

The coating was constructed by initially depositing a single layer using Physical Vapor Deposition (PVD) to study the shielding properties of each individual layer prior to multi-layering. As shown in Figure. 1, the inner layer composed of TiN serves as a diffusional barrier to prevent the interaction between the multi-layer coatings and the inner stainless steel canister $[4,18]$. The middle layer composed of $\mathrm{ZrO}_{2}+\mathrm{TiO}_{2}+\mathrm{Al}_{2} \mathrm{O}_{3}$ is formed using a tri-oxide layer known as zirconia titania alumina, which improves the stainless steel canister's corrosion resistance [4, 19]. The third layer composed of 
$\mathrm{MoS}_{2}$ serves as a lubricant to ease the handling and transportation of the drycask and prevent micro cracking [4, 20]. The dimensions of the coated samples are measured, and their volumes and densities are calculated and tabulated in Table 1, in which each coating layer is $100 \mu \mathrm{m}$ thick. The concrete overpack are represented by samples marked as $\mathrm{CN}$ and $\mathrm{CZ}$ and their dimensions and volumes are measured and their densities are calculated as listed in Table 2, while Table 3 shows their basic chemical compositions, which is typical for both $\mathrm{CN}$ and $\mathrm{CZ}$ mixes except that $\mathrm{CN}$ has a small fraction of lead powder in the composition. The number of gamma-ray sources used in this work is shown in Tale 4 along with their activities and photon energies.

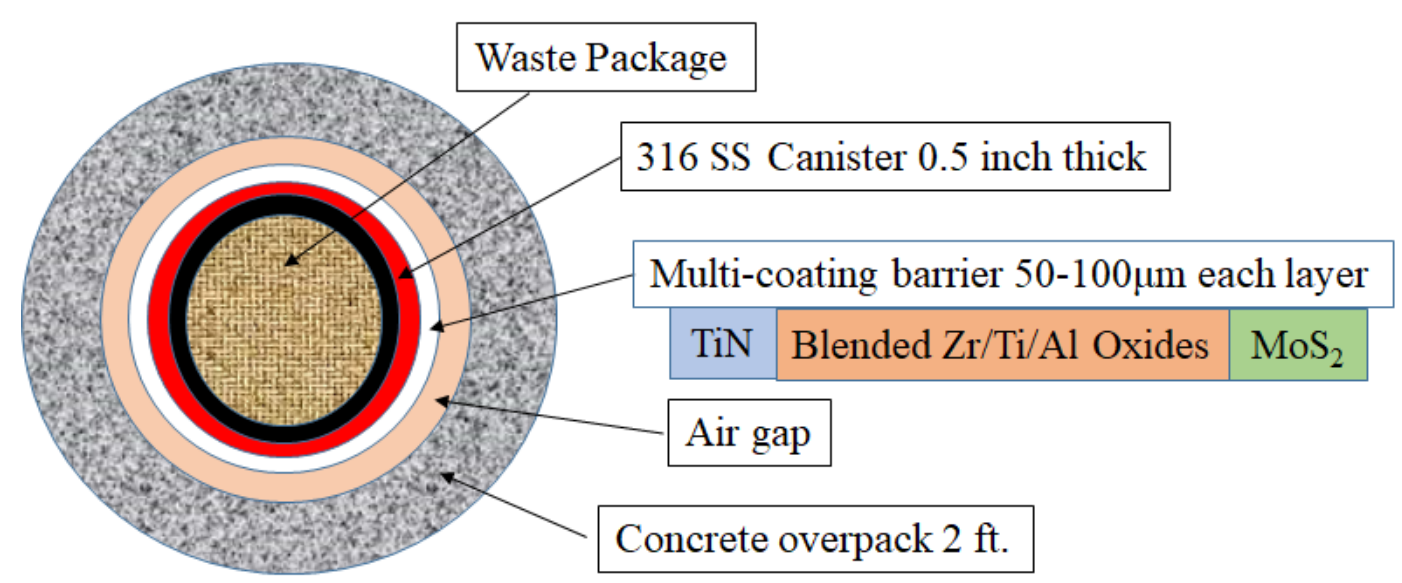

Figure 1: Concept of Waste Package (Not to Scale) with Multi-Layered Shielding on the Canister [4-6].

Table 1: Dimensions of 316SS Coated Samples and their Calculated Volumes and Densities

\begin{tabular}{|l|c|c|c|c|c|}
\hline Coating Layer & Weight $(\mathbf{g})$ & Diameter $(\mathbf{c m})$ & Height $(\mathbf{c m})$ & $\begin{array}{c}\text { Calculated } \\
\text { Volume }\left(\mathbf{c m}^{3}\right)\end{array}$ & $\begin{array}{c}\text { Calculated } \\
\text { Density }\left(\mathbf{g} / \mathbf{c m}^{\mathbf{3}}\right)\end{array}$ \\
\hline $\mathrm{TiO}_{2}$ & 5.96826 & 2.542 & 0.16 & 0.813 & 7.3454 \\
\hline $\mathrm{ZrO} 2$ & 5.9424 & 2.542 & 0.16 & 0.813 & 7.3136 \\
\hline $\mathrm{TiN}$ & 5.96478 & 2.542 & 0.16 & 0.813 & 7.3411 \\
\hline $\mathrm{MoS}_{2}$ & 5.97757 & 2.542 & 0.16 & 0.813 & 7.3569 \\
\hline $\mathrm{Al}_{2} \mathrm{O}_{3}$ & 6.0034 & 2.542 & 0.16 & 0.813 & 7.3886 \\
\hline $\mathrm{ZrO}_{2}+\mathrm{TiO}_{2}$ & 5.71846 & 2.542 & 0.16 & 0.813 & 7.0380 \\
\hline
\end{tabular}

Table 2: Measured Dimensions of Concrete Overpack Samples and their Calculated Densities and Volumes

\begin{tabular}{|c|c|c|c|c|c|}
\hline Sample & Weight $(\mathbf{g})$ & Diameter $(\mathbf{c m})$ & Height $(\mathbf{c m})$ & $\begin{array}{c}\text { Calculated } \\
\text { Volume }\left(\mathbf{c m}^{\mathbf{3}}\right)\end{array}$ & Calculated Density $\left(\mathbf{g} / \mathbf{c m}^{\mathbf{3}}\right)$ \\
\hline $\mathrm{CN}$ & 3597.4 & 10.2 & 20.0 & 1634.3 & 2.2 \\
\hline $\mathrm{CZ}$ & 3563.8 & 10.5 & 20.5 & 1775.1 & 2.0 \\
\hline
\end{tabular}

Table 3: Basic Chemical Compositions of Concrete Overpack Samples

\begin{tabular}{|c|c|c|c|}
\hline Sample & High-Density Concrete (\%) & Boron (\%) & Granite (\%) \\
\hline $\mathrm{CN}$ & $50 \%$ & $25 \%$ & $25 \%$ \\
\hline $\mathrm{CZ}$ & $50 \%$ & $25 \%$ & $25 \%$ \\
\hline
\end{tabular}

Table 4: Number of Gamma-Ray Sources with their Activities and Photon Energies

\begin{tabular}{|c|c|c|c|}
\hline Source & Number & Activity $(\boldsymbol{\mu C i})$ & Photon Energy $(\mathbf{M e V})$ \\
\hline Ba-133 & 1 & 1 & $0.302,0.356$ \\
\hline Cs-137 & 1 & 1 & 0.662 \\
\hline Co-60 & 3 & 3 & $1.173,1.332$ \\
\hline
\end{tabular}




\subsection{Methods}

Single-layer or double-layer coated 316 stainless steel samples were tested for their gamma ray attenuation experimentally and computationally. The concrete samples of various compositions were tested experimentally as overpack materials. The experimental setup is shown in Figure. 2, in which the gamma radiation sources are placed on the bottom base and collimated by lead collimator. The sample (concrete overpack or coated 316 stainless steel) is placed on top of the collimator and the detector is placed on the top of the sample. The detector is an integrated ORTEC digibase detector "NaI" with PM tube base combined with an amplifier, its high-voltage power supply and connected to a computer with Maestro software. Collimation is applied by using lead bricks to narrow the beam of gamma rays and direct it toward the detector. The measurements were carried out for 30 minutes counting time for each sample. Measuring gamma-ray attenuation is determined by measuring the fractional radiation intensity, $I$, passing through the shielding material of thickness, $x$, as compared to the source intensity, $I_{o}$, and thus, the linear attenuation coefficient, $\mu$, is obtained as following [1]:

$$
I=I_{o} e^{-\mu x}
$$

The computational tool used in this work, MicroShield ${ }^{\circledR}$ v9.05 (MSD9) software package [21] is used to calculate the attenuation coefficients and half-value layer (HVL) of coated 316 stainless steel samples according to the measured density and material compositions, and then compare it to the experimentally measured values. Figure 3 shows the computational setup for coated 316 stainless steel samples. The source dimensions are $1.27 \mathrm{~cm}$ radius and $1.5 \mathrm{~cm}$ height. The air gap is $9.398 \mathrm{~cm}$ then placed on the holder a coated 316 stainless steel sample of $0.16 \mathrm{~cm}$ height with either a single coating layer of $100 \mu \mathrm{m}$ thickness or a double coating layer of $50 \mu \mathrm{m}$ thickness each, where the dose is measured at a distance of $15.24 \mathrm{~cm}$ from the bottom.

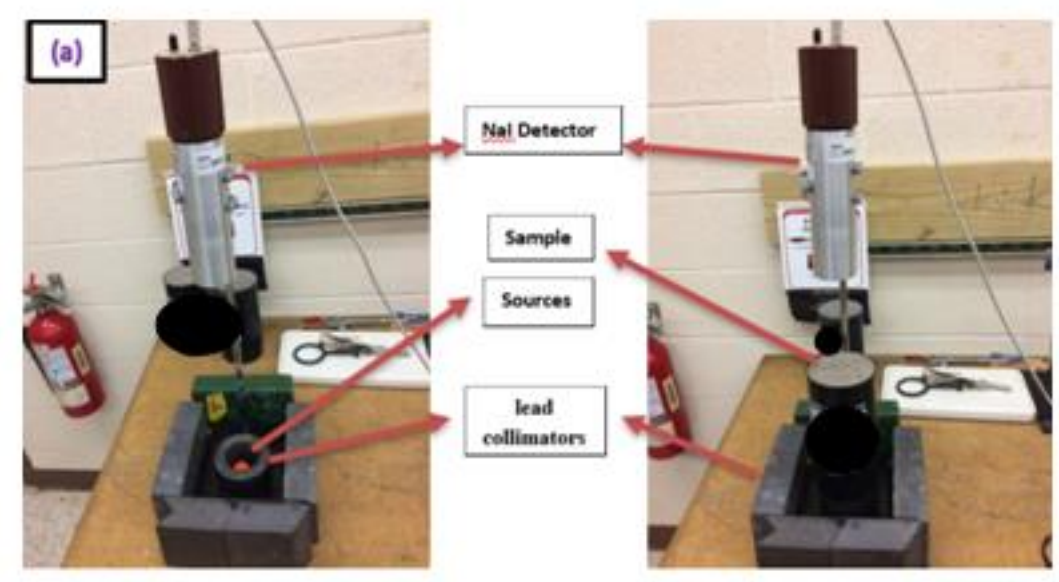




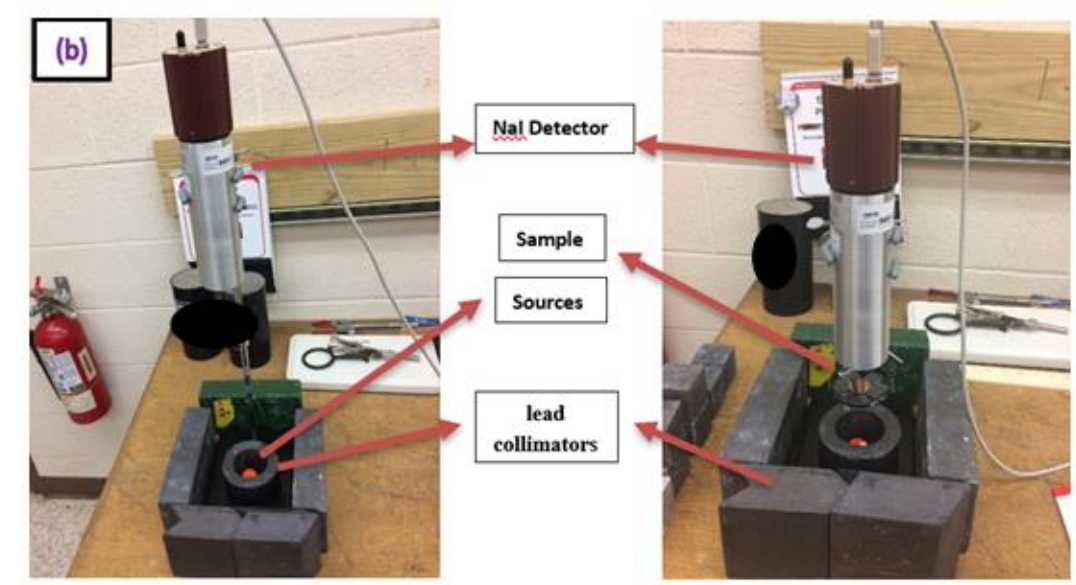

Figure 2: Experimental Setup for Measuring Gamma-ray Attenuation in Concrete Overpack (a) and Coated 316 Stainless steel Samples (b).

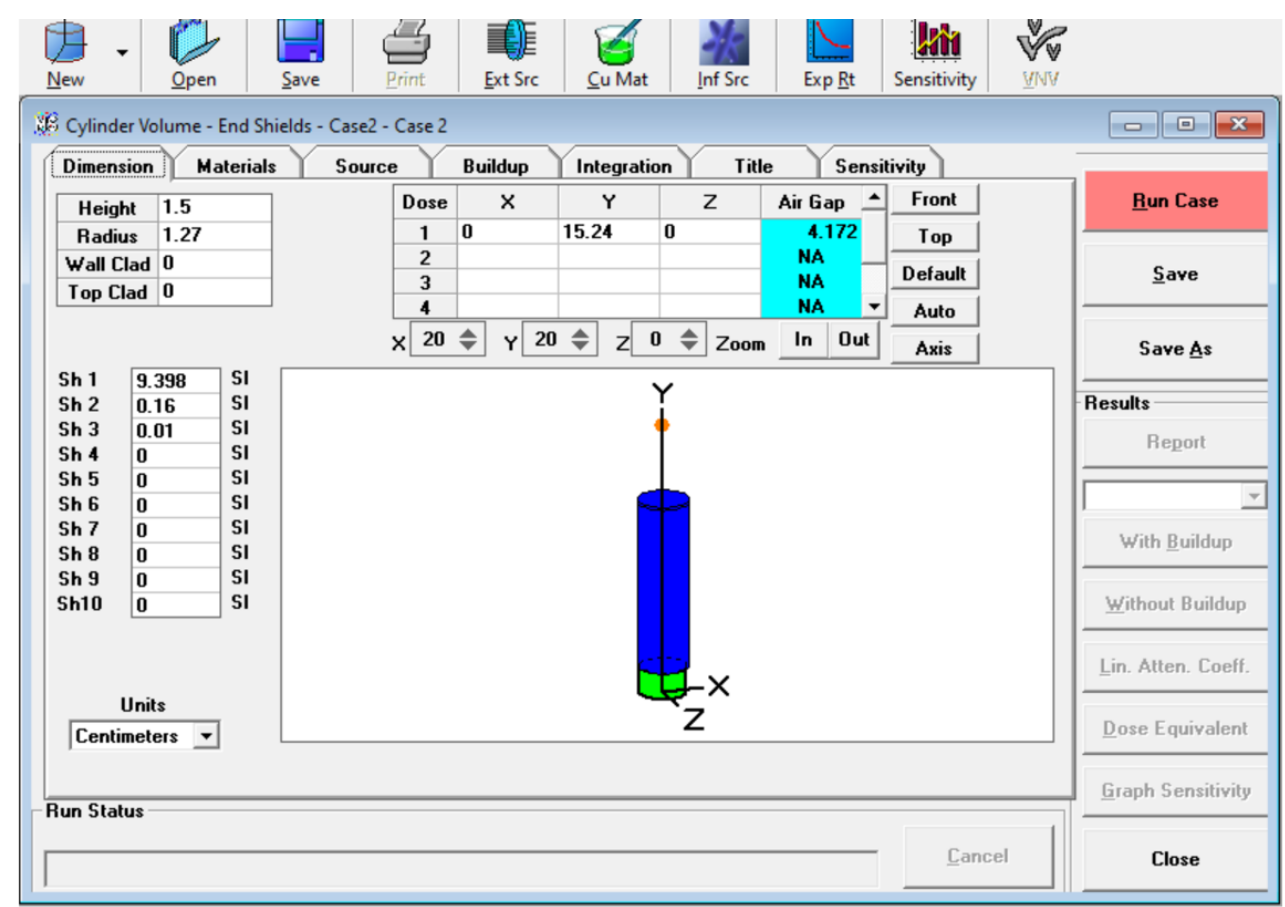

Figure 3: Computational Setup in MicroShield for Calculation of Gamma-Ray Attenuation in Coated 316 Stainless Steel Samples.

\section{RESULTS AND DISCUSSION}

\subsection{Shielding Properties of Coated 316 Stainless Steel}

The measured counts in coated 316 stainless steel samples using gamma-ray sources are plotted in Figure. 4, in which the peaks associated with each gamma-ray source are significantly shown during the background counting (no sample). The energy peaks of Ba-133 source correspond to $0.302 \mathrm{MeV}$ and $0.356 \mathrm{MeV}$ while Cs-137 energy peak corresponds to 0.662 $\mathrm{MeV}$ and Co-60 energy peaks correspond to $1.173 \mathrm{MeV}$ and $1.332 \mathrm{MeV}$. After placing the coated 316 stainless steel samples for counting, the measured counts start to decrease with respect to the energy peaks of gamma-ray sources and the highest reduction in the measured counts is observed at low photon energy peaks which indicates a better attenuation effectiveness against gamma radiation. 


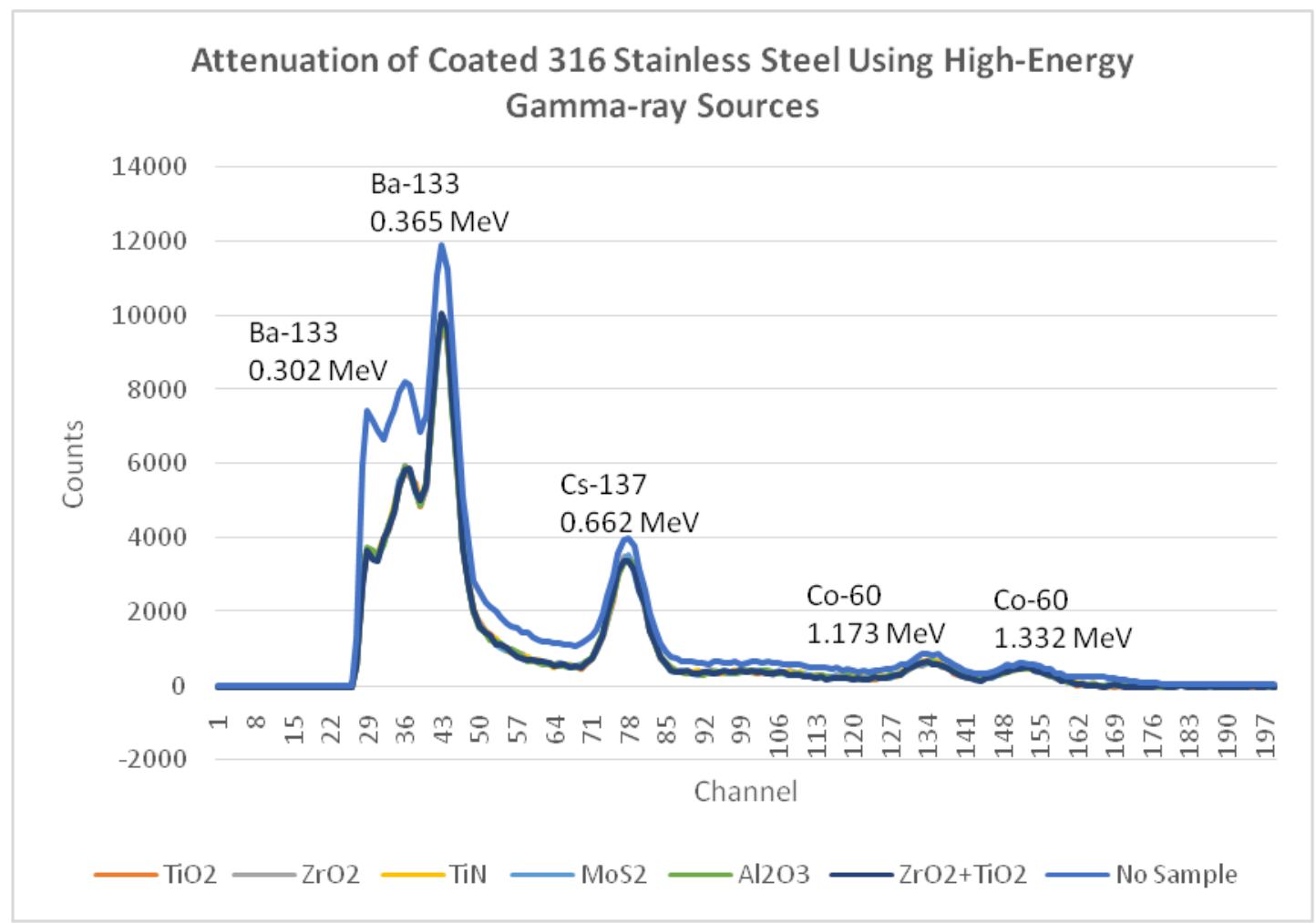

Figure 4: Measured Counts in Coated SS316 Samples using Gamma-Ray Sources.

Table 5 and Figure 5(a) show the measured linear attenuation coefficient as function of photon energy for coated 316 stainless steel samples using gamma-ray sources while Table 6 and Figure. 5(b) show the measured mass attenuation coefficient. As shown, there is a dramatic decrease in attenuation coefficients from $0.302 \mathrm{MeV}$ to $0.356 \mathrm{MeV}$ photon energy peak then a fluctuation at higher photon energies. Comparing measured attenuation coefficients of coated 316 stainless steel samples at each energy at a time, it is clear that 316 stainless steel coated with $\mathrm{TiO}_{2}$ single layer gives the highest linear and mass attenuation coefficients at $0.302,0.356$ and $1.332 \mathrm{MeV}$ photon energy peaks, while at $0.662 \mathrm{MeV}$ the 316 stainless steel coated with $\mathrm{MoS}_{2}$ single layer gives the highest values of attenuation coefficients.

At $1.173 \mathrm{MeV}$ on the other hand, 316 stainless steel coated with $\mathrm{ZrO}_{2}+\mathrm{TiO}_{2}$ double layers gives the highest linear and mass attenuation coefficients values due to their combined density $\left(7.038 \mathrm{~g} / \mathrm{cm}^{3}\right)$ as shown in Table 5 and 6 . Also, 316 stainless steel coated with $\mathrm{Al}_{2} \mathrm{O}_{3}$ exhibits the lowest attenuation coefficients at most photon energies due to its high density $\left(7.3886 \mathrm{~g} / \mathrm{cm}^{3}\right)$ while samples coated with $\mathrm{ZrO}_{2}$ and $\mathrm{TiN}$ single layers exhibit a reduction in the attenuation coefficients at selected energies. Moreover, there is a significant difference in the measured attenuation coefficients among all coatings at photon energy peaks ranging from $0.662 \mathrm{MeV}$ to $1.332 \mathrm{MeV}$.

Table 5: Measured Linear Attenuation Coefficient at Photon Energy Peaks for the Coated SS316 Samples

\begin{tabular}{|c|c|c|c|c|c|c|}
\hline $\begin{array}{l}\text { Photon } \\
\text { Energy } \\
(\mathrm{MeV})\end{array}$ & $\begin{array}{c}\mathrm{TiO}_{2}{ }^{*} \mu " \\
\left(\mathrm{~cm}^{-1}\right)\end{array}$ & $\begin{array}{c}\mathrm{ZrO}_{2}{ }^{"} " \mu " \\
\left(\mathrm{~cm}^{-1}\right)\end{array}$ & $\operatorname{TiN}$ “ $\mu$ ” $\left(\mathrm{cm}^{-1}\right)$ & $\begin{array}{c}\operatorname{MoS}_{2} " \mu " \mu \\
\left(\mathrm{cm}^{-1}\right)\end{array}$ & $\mathrm{Al}_{2} \mathrm{O}_{3}$ " $\mu$ " $\left(\mathrm{cm}^{-1}\right)$ & $\begin{array}{c}\mathrm{ZrO}_{2}+\mathrm{TiO}_{2} \\
{ }^{6}{ } " \\
\left(\mathrm{~cm}^{-1}\right)\end{array}$ \\
\hline 0.302 & 2.257937387 & 2.1768528 & 2.160544188 & 2.107564025 & 2.055029193 & 2.044361841 \\
\hline 0.356 & 1.242407976 & 1.064808686 & 1.131212037 & 1.184974449 & 1.125546528 & 1.063562549 \\
\hline 0.662 & 1.155141806 & 0.898725698 & 0.892975046 & 1.282305889 & 0.752775169 & 1.117293085 \\
\hline 1.173 & 1.522907419 & 1.08970867 & 1.034152748 & 1.562907556 & 1.136385511 & 1.80843831 \\
\hline 1.332 & 1.429347263 & 1.257741975 & 1.376042036 & 1.116129325 & 0.7334827 & 0.830009715 \\
\hline
\end{tabular}


Table 6: Measured Mass Attenuation Coefficient at Photon Energy Peaks for the Coated SS316 Samples

\begin{tabular}{|c|c|c|c|c|c|c|}
\hline $\begin{array}{l}\text { Photon } \\
\text { Energy } \\
(\mathrm{MeV})\end{array}$ & $\begin{array}{c}\mathrm{TiO}_{2} " \mu / \mu / \rho " \\
\left(\mathrm{~g} / \mathrm{cm}^{2}\right)\end{array}$ & $\begin{array}{c}\mathrm{ZrO}_{2} " \mu / \mu / \rho " \\
\left(\mathrm{~g} / \mathrm{cm}^{2}\right)\end{array}$ & $\begin{array}{c}\text { TiN “ } \boldsymbol{\mu} / \mathbf{\rho} ” \\
\left(\mathrm{~g} / \mathrm{cm}^{2}\right)\end{array}$ & $\begin{array}{c}\operatorname{MoS}_{2} " \mu / \rho " \rho \\
\left(g / \mathrm{cm}^{2}\right)\end{array}$ & $\begin{array}{c}\mathrm{Al}_{2} \mathrm{O}_{3} " \mu / \mu / \rho ” \\
\left(\mathrm{~g} / \mathrm{cm}^{2}\right)\end{array}$ & $\begin{array}{c}\mathrm{ZrO}_{2}+\mathrm{TiO}_{2} " \mu \\
/ \rho "\left(\mathrm{~g} / \mathrm{cm}^{2}\right)\end{array}$ \\
\hline 0.302 & 0.307394764 & 0.297645613 & 0.294307296 & 0.286476111 & 0.27813332 & 0.290476487 \\
\hline 0.356 & 0.169140964 & 0.145593508 & 0.154092639 & 0.161070728 & 0.152334572 & 0.15111802 \\
\hline 0.662 & 0.15726058 & 0.122884635 & 0.12164022 & 0.174300756 & 0.101882668 & 0.158752411 \\
\hline 1.173 & 0.207328055 & 0.148998134 & 0.140871314 & 0.212442266 & 0.15380155 & 0.256954908 \\
\hline 1.332 & 0.19459081 & 0.171973678 & 0.187443151 & 0.151712776 & 0.099271572 & 0.117933284 \\
\hline
\end{tabular}
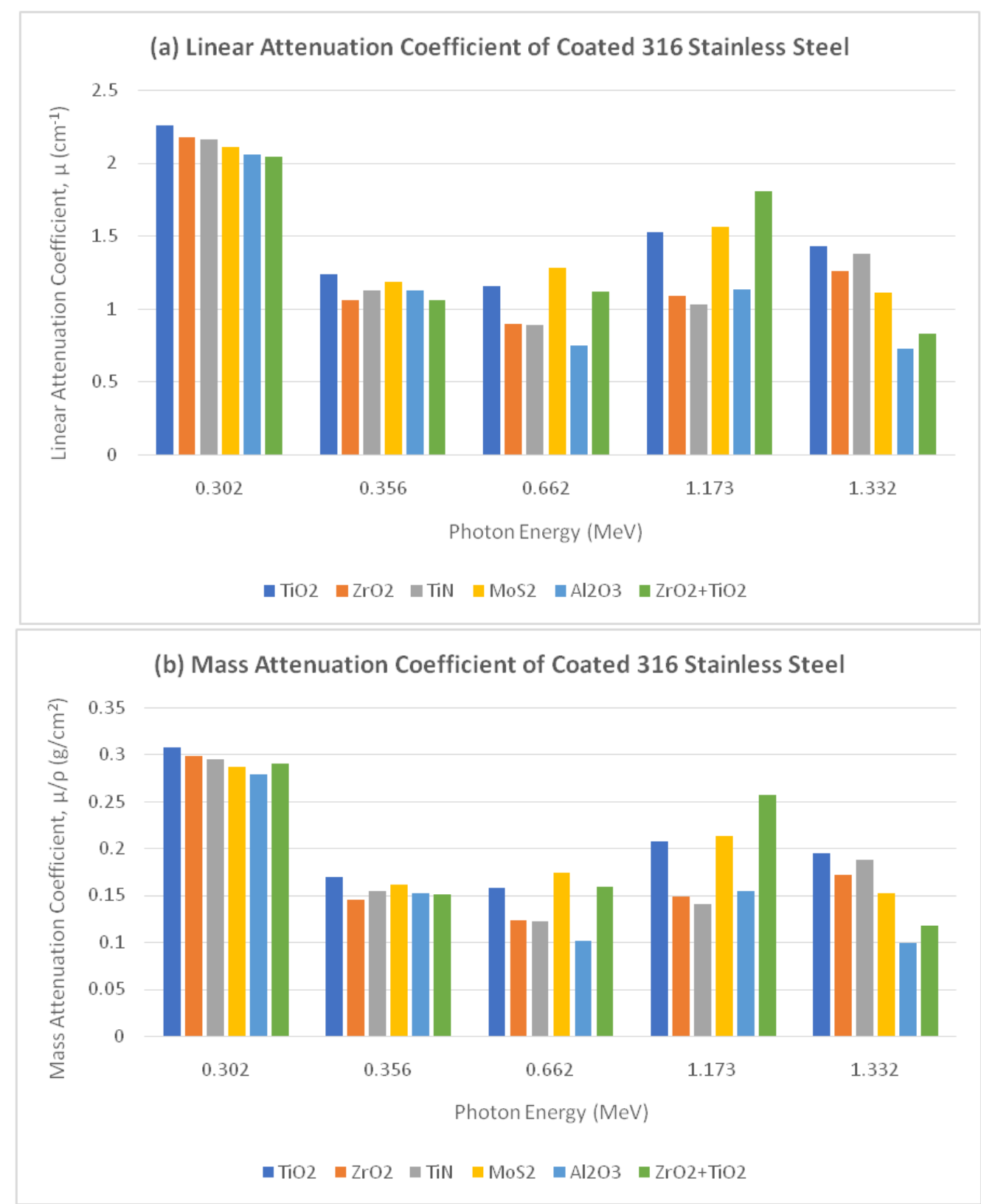

Figure 5: Measured Linear (a) and Mass (b) Attenuation Coefficients vs. photon Energy for the Coated SS316 Samples.

Computational results of the coated 316 stainless steel samples, Figure 6, using MicroShield ${ }^{\circledR}$ software comparing 
linear and mass attenuation coefficients obtained experimentally and computationally at each photon energy peak. As shown, the experimental values of linear and mass attenuation coefficients are higher than the values obtained computationally at $0.302 \mathrm{MeV}$ and $1.173 \mathrm{MeV}$ photon energy peaks except for 316 stainless steel coated with $\mathrm{ZrO}_{2}+\mathrm{TiO}_{2}$ double layers in which the computational attenuation coefficients are higher than the experimental ones. However, the difference between the experimental and computational values is reversed at $0.356 \mathrm{MeV}$ and fluctuated at $0.662 \mathrm{MeV}$ and $1.332 \mathrm{MeV}$ photon energy peaks. Furthermore, the highest linear attenuation coefficient is observed computationally at $0.302 \mathrm{MeV}$ with a value of $2.4648 \mathrm{~cm}^{-1}$ for 316 stainless steel coated with $\mathrm{ZrO}_{2}+\mathrm{TiO}_{2}$ double layers while the lowest linear attenuation coefficient is observed experimentally at $1.332 \mathrm{MeV}$ with a value of $0.7335 \mathrm{~cm}^{-1}$ for 316 stainless steel coated with $\mathrm{Al}_{2} \mathrm{O}_{3}$ single layer.

It is computationally shown that the highest mass attenuation coefficient is at $0.302 \mathrm{MeV}$ with a value of 0.350 $\mathrm{g} / \mathrm{cm}^{2}$ for 316 stainless steel coated with $\mathrm{ZrO}_{2}+\mathrm{TiO}_{2}$ double layers, in which the combined density is $7.038 \mathrm{~g} / \mathrm{cm}^{3}$. The lowest mass attenuation coefficient is observed experimentally at $1.332 \mathrm{MeV}$ with a value of $0.0993 \mathrm{~g} / \mathrm{cm}^{2}$ for 316 stainless steel coated with $\mathrm{Al}_{2} \mathrm{O}_{3}$ which has a density of $7.3886 \mathrm{~g} / \mathrm{cm}^{3}$. The computational attenuation coefficients values seem to decrease with increasing photon energy while the experimental values fluctuate due to a $20 \%$ experimental error, environmental effect and instrument sensitivity.

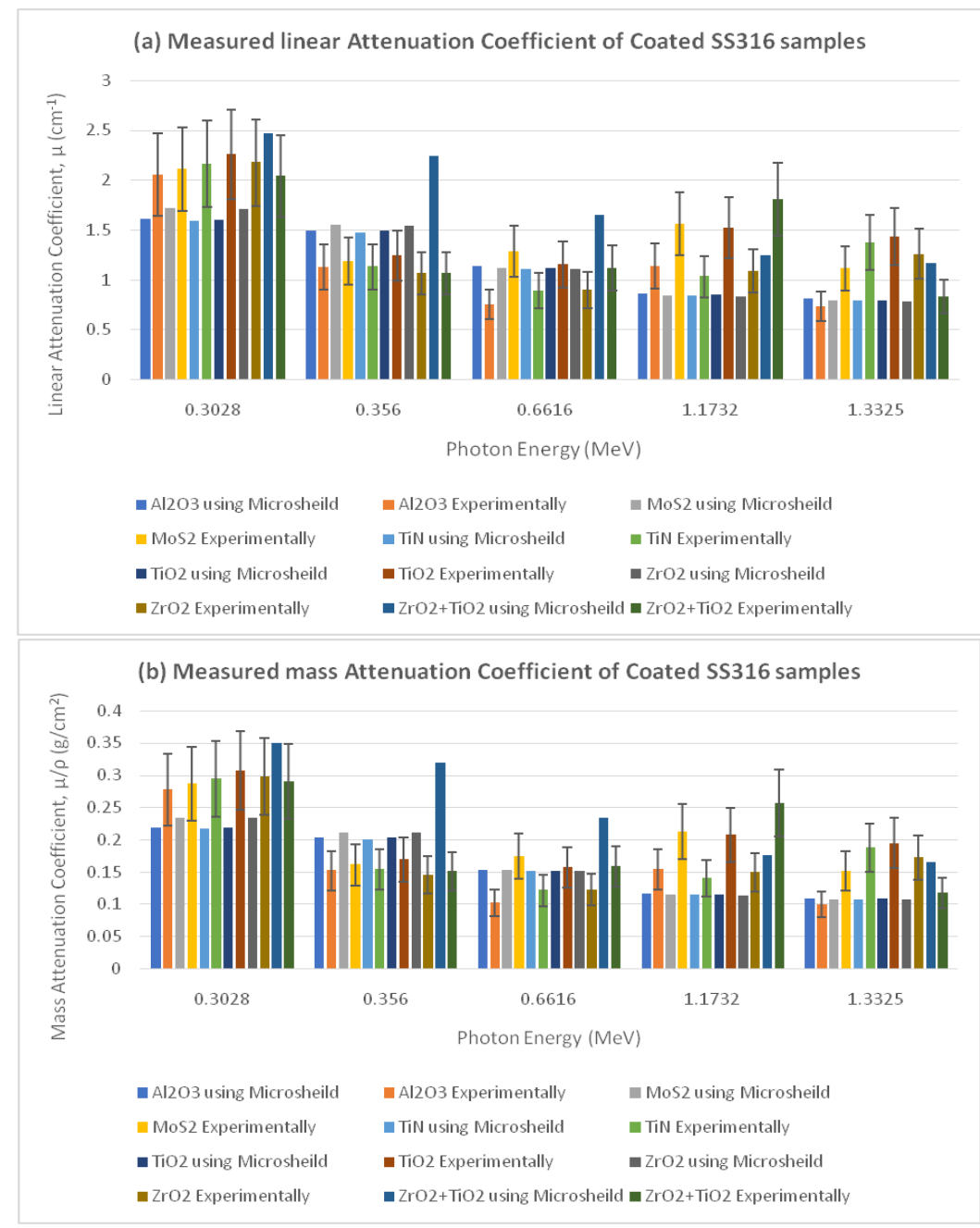

Figure 6: Comparison of Linear (a) and Mass (b) Attenuation Coefficients vs. Photon energy for the Coated SS316 Samples using Gamma-Ray Sources. 
Another shielding property that is important in radiation shielding assessments is the half-value layer (HVL) defined as the thickness of the target material at which the radiation intensity is reduced by one half and it is calculated as following [1]:

$$
H V L=\frac{\ln (2)}{\mu}
$$

Thus, the lower the HVL, the better the attenuation efficiency due to a small volume required to attenuate the same amount of radiation [1]. Table 7 and Figure 7 show the HVL values obtained experimentally for the coated 316 stainless steel samples using gamma-ray sources. As shown, the maximum HVL value of $0.945 \mathrm{~cm}$ is observed at 1.332 $\mathrm{MeV}$ photon energy peak for 316 stainless steel coated with $\mathrm{Al}_{2} \mathrm{O}_{3}$ while the lowest $\mathrm{HVL}$ value of $0.307 \mathrm{~cm}$ is observed at $0.302 \mathrm{MeV}$ for 316 stainless steel coated with $\mathrm{TiO}_{2}$. Also, there is a gradual increase in the HVL with increasing photon energy from $0.302 \mathrm{MeV}$ to $0.356 \mathrm{MeV}$ then a fluctuation up to $1.332 \mathrm{MeV}$ photon energy peak.

Figure 8 shows comparison between HVL values obtained experimentally and computationally for the coated 316 stainless steel samples. The HVL values obtained computationally using MicroShield ${ }^{\circledR}$ are higher than the values obtained experimentally at $0.302 \mathrm{MeV}$ and $1.173 \mathrm{MeV}$ photon energy peaks except for 316 stainless steel coated with $\mathrm{ZrO}_{2}+\mathrm{TiO}_{2}$ double layers in which the experimental HVL value is higher than the computational one at $0.302 \mathrm{MeV}$. The difference between the experimental and computational values is reversed at $0.356 \mathrm{MeV}$ and fluctuated at $0.662 \mathrm{MeV}$ and $1.332 \mathrm{MeV}$ photon energy peaks. Moreover, the HVL values increase at first from $0.302 \mathrm{MeV}$ to $0.356 \mathrm{MeV}$ photon energy peak then start to fluctuate at increasing photon energy.

Table 7: Half-Value Layer (HVL) Values at Photon Energy Peaks for the Coated SS316 Samples

\begin{tabular}{|c|c|c|c|c|c|c|}
\hline $\begin{array}{c}\text { Photon Energy } \\
(\mathbf{M e V})\end{array}$ & $\mathbf{T i O}_{\mathbf{2}}(\mathbf{c m})$ & $\mathrm{ZrO}_{\mathbf{2}}(\mathbf{c m})$ & $\mathbf{T i N}(\mathbf{c m})$ & $\mathbf{M o S}_{\mathbf{2}}(\mathbf{c m})$ & $\mathbf{A l}_{\mathbf{2}} \mathbf{O}_{\mathbf{3}}(\mathbf{c m})$ & $\mathbf{Z r O}_{\mathbf{2}}+\mathbf{T i O}_{\mathbf{2}}(\mathbf{c m})$ \\
\hline 0.302 & 0.306982463 & 0.318417111 & 0.320820645 & 0.328885468 & 0.337293107 & 0.339053081 \\
\hline 0.356 & 0.557906255 & 0.65095936 & 0.612747352 & 0.584946942 & 0.615831654 & 0.651722065 \\
\hline 0.662 & 0.600053757 & 0.771255547 & 0.776222341 & 0.540547452 & 0.920789113 & 0.620380803 \\
\hline 1.173 & 0.455147287 & 0.636084854 & 0.670256093 & 0.443498515 & 0.609957777 & 0.383284946 \\
\hline 1.332 & 0.484939663 & 0.551104435 & 0.503725295 & 0.621027658 & 0.94500822 & 0.83510731 \\
\hline
\end{tabular}




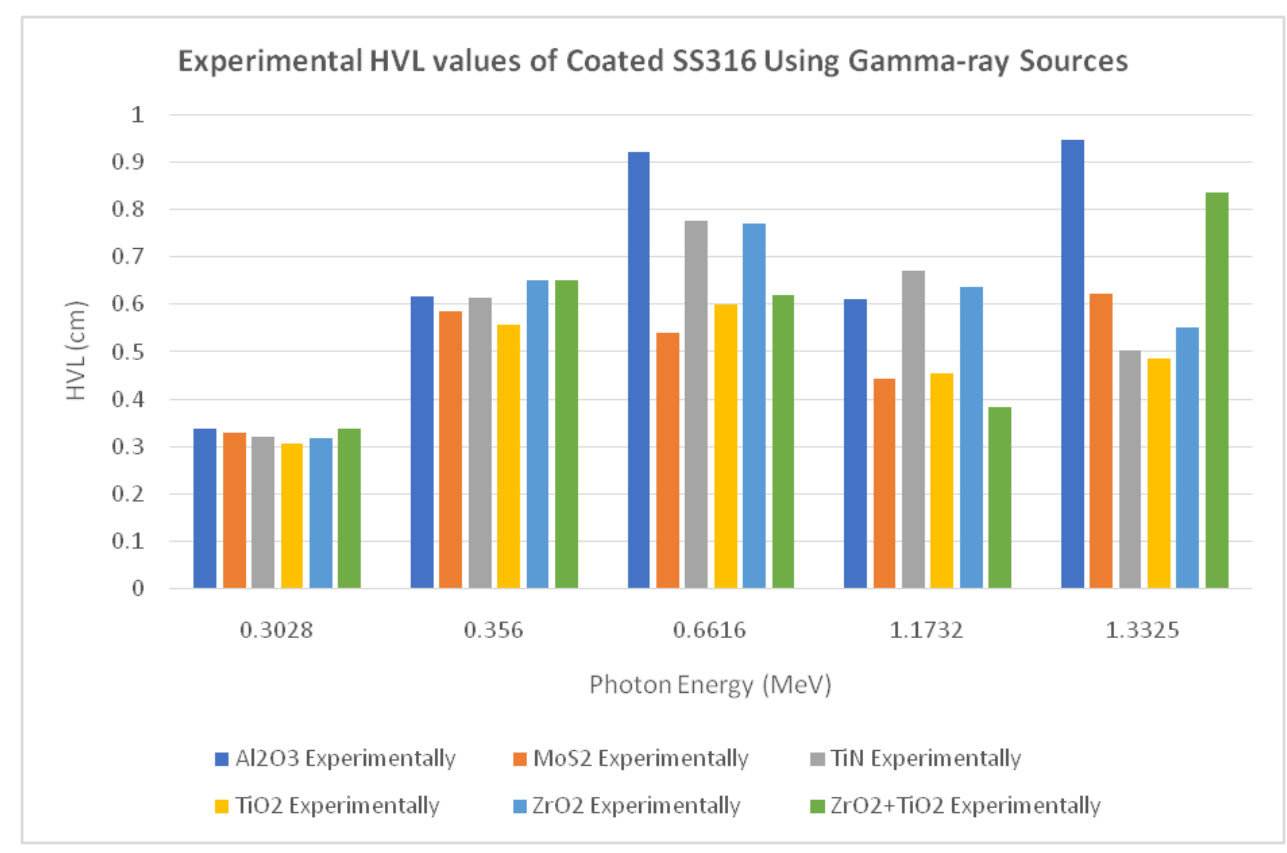

Figure 7: Variation of the Measured Half-Value Layer (HVL) vs. Photon Energy for Coated SS316 Samples.

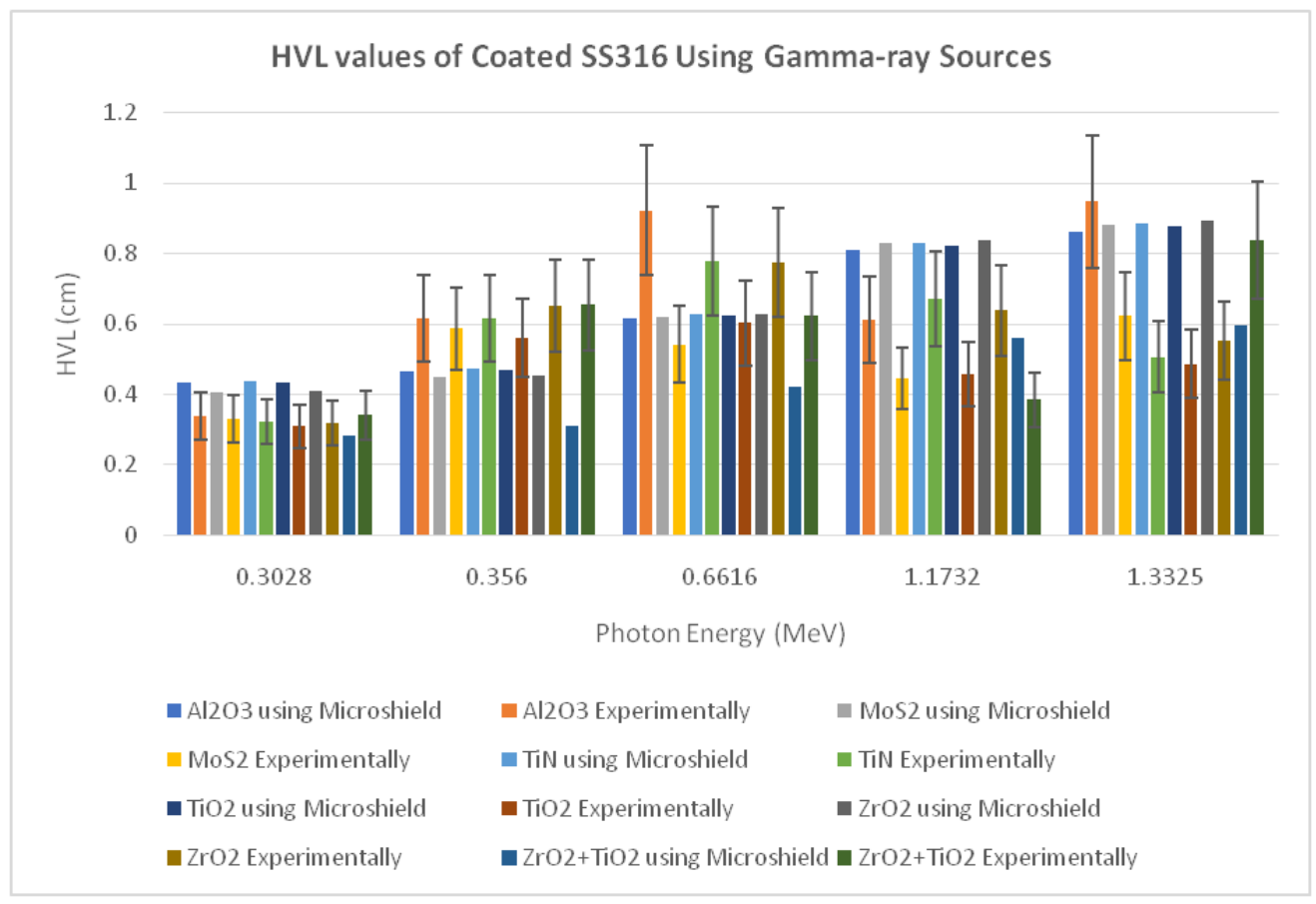

Figure 8: Comparison of the Half-Value Layer (HVL) vs. Photon Energy for the Coated SS316 Samples.

\subsection{Shielding Properties of Concrete Overpack}

The measured counts in concrete overpack samples are plotted in Figure. 9 for gamma-ray sources, in which the peaks associated with each photon energy are shown during the background counting (no sample). As shown, the energy peaks of Ba-133 source correspond to $0.302 \mathrm{MeV}$ and $0.356 \mathrm{MeV}$ while Cs-137 energy peak corresponds to $0.662 \mathrm{MeV}$ and Co-60 
energy peaks correspond to $1.173 \mathrm{MeV}$ and $1.332 \mathrm{MeV}$. The energy peaks of gamma-ray sources barely appear after putting the concrete overpack samples in the measuring place, which indicate a better attenuation effectiveness against gamma radiation.

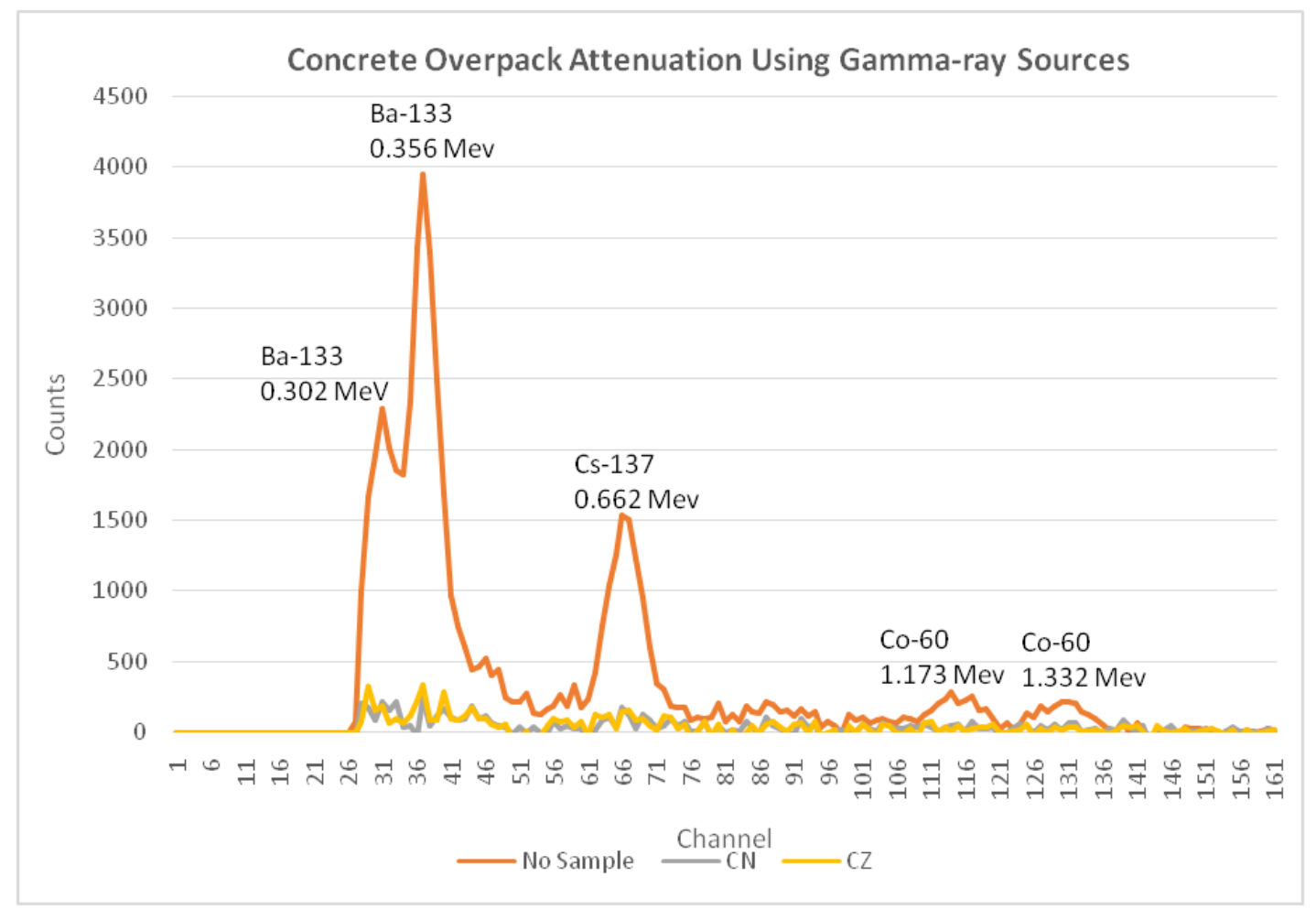

Figure 9: Measured Counts in Concrete Overpack using Gamma-Ray Sources.

Table 8 and Figure 10(a) show the measured linear attenuation coefficient as function of photon energy for concrete overpack samples while Table 9 and Figure. 10(b) show the measured mass attenuation coefficient. As shown in Figure. 9, there is a gradual increase from $0.302 \mathrm{MeV}$ to $0.356 \mathrm{MeV}$ photon energy peak then a gradual decrease up to $1.332 \mathrm{MeV}$, except for $\mathrm{CZ}$ sample in which the linear and mass attenuation coefficients increase again at $1.332 \mathrm{MeV}$. Also, the highest attenuation occurs for $\mathrm{CZ}$ sample at $0.356 \mathrm{MeV}$ photon energy peak compared to $\mathrm{CN}$ while the lowest attenuation occurs for $\mathrm{CN}$ sample at $1.332 \mathrm{MeV}$. Furthermore, due to the low density of $\mathrm{CZ}\left(2.0 \mathrm{~g} / \mathrm{cm}^{3}\right)$ compared to $\mathrm{CN}$ $\left(2.2 \mathrm{~g} / \mathrm{cm}^{3}\right)$, it exhibits better mass attenuation coefficient than $\mathrm{CN}$ sample except at $0.662 \mathrm{MeV}$ photon energy peak due to its reduced linear attenuation coefficient at this energy.

Table 8: Linear Attenuation Coefficient at Photon Energy Peaks for the Concrete Overpack Samples

\begin{tabular}{|c|c|c|}
\hline Photon Energy (MeV) & $\begin{array}{c}\text { Linear Attenuation Coefficient “ } \boldsymbol{\mu} \text { ”" } \\
\left(\mathbf{c m}^{\mathbf{- 1}}\right) \text { for } \mathbf{C N}\end{array}$ & $\begin{array}{c}\text { Linear Attenuation Coefficient “ } \boldsymbol{\mu} \text { ” } \\
\left(\mathbf{c m}^{\mathbf{- 1}}\right) \text { for } \mathbf{C Z}\end{array}$ \\
\hline 0.302 & 0.118217908 & 0.122140857 \\
\hline 0.356 & 0.151567035 & 0.164121227 \\
\hline 0.662 & 0.124846542 & 0.111869848 \\
\hline 1.173 & 0.068588313 & 0.068828633 \\
\hline 1.332 & 0.05806417 & 0.088323315 \\
\hline
\end{tabular}


Table 9: Mass Attenuation Coefficient at Photon Energy Peaks for the Concrete Overpack Samples

\begin{tabular}{|c|c|c|}
\hline Photon Peak (MeV) & $\begin{array}{l}\text { Mass Attenuation Coefficient } \\
" \omega \mu / \rho "\left(\mathrm{~g} / \mathrm{cm}^{2}\right) \text { for } \mathrm{CN}\end{array}$ & $\begin{array}{l}\text { Mass Attenuation Coefficient } \\
" \omega \mu / \rho "\left(\mathrm{~g} / \mathrm{cm}^{2}\right) \text { for } \mathrm{CZ}\end{array}$ \\
\hline 0.302 & 0.053735413 & 0.061070429 \\
\hline 0.356 & 0.068894107 & 0.082060613 \\
\hline 0.662 & 0.056748428 & 0.055934924 \\
\hline 1.173 & 0.031176506 & 0.034414316 \\
\hline 1.332 & 0.026392804 & 0.044161657 \\
\hline
\end{tabular}
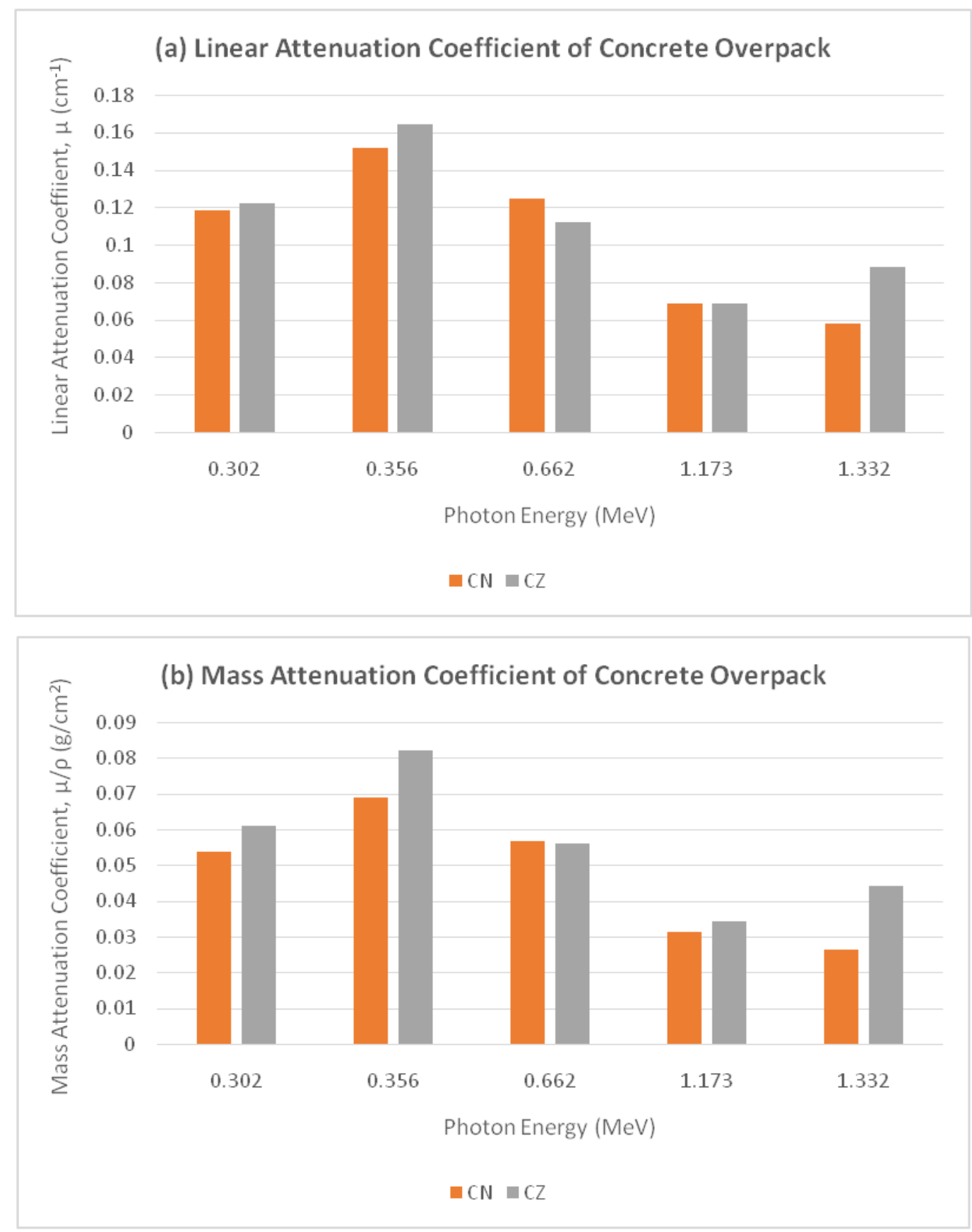

Figure 10: Measured Linear (a) and Mass (b) Attenuation Coefficients vs. Photon Energy for the Concrete Overpack Samples. 
Table 10 and Figure 11 show the HVL values obtained experimentally for the concrete overpack samples. As shown, the maximum value of $\mathrm{HVL}$ is at $1.332 \mathrm{MeV}$ photon energy peak for $\mathrm{CN}$ sample while the lowest value is at 0.356 $\mathrm{MeV}$ for $\mathrm{CZ}$ sample due to its high attenuation coefficients. There is also a gradual decrease in the HVL with increasing photon energy from $0.302 \mathrm{MeV}$ to $0.356 \mathrm{MeV}$ then a gradual increase up to $1.332 \mathrm{MeV}$ photon energy peak except for $\mathrm{CZ}$ sample, which exhibits a drop in the HVL compared to CN sample.

Table 10: Half-Value Layer (HVL) Values at Photon Energy Peaks for the Concrete Overpack Samples

\begin{tabular}{|c|c|c|}
\hline Photon Peak (MeV) & HVL (cm) for CN & HVL (cm) for CZ \\
\hline 0.302 & 5.863301005 & 5.674982108 \\
\hline 0.356 & 4.573205383 & 4.223385326 \\
\hline 0.662 & 5.551993421 & 6.196014314 \\
\hline 1.173 & 10.10590799 & 10.07062253 \\
\hline 1.332 & 11.93760598 & 7.847839295 \\
\hline
\end{tabular}

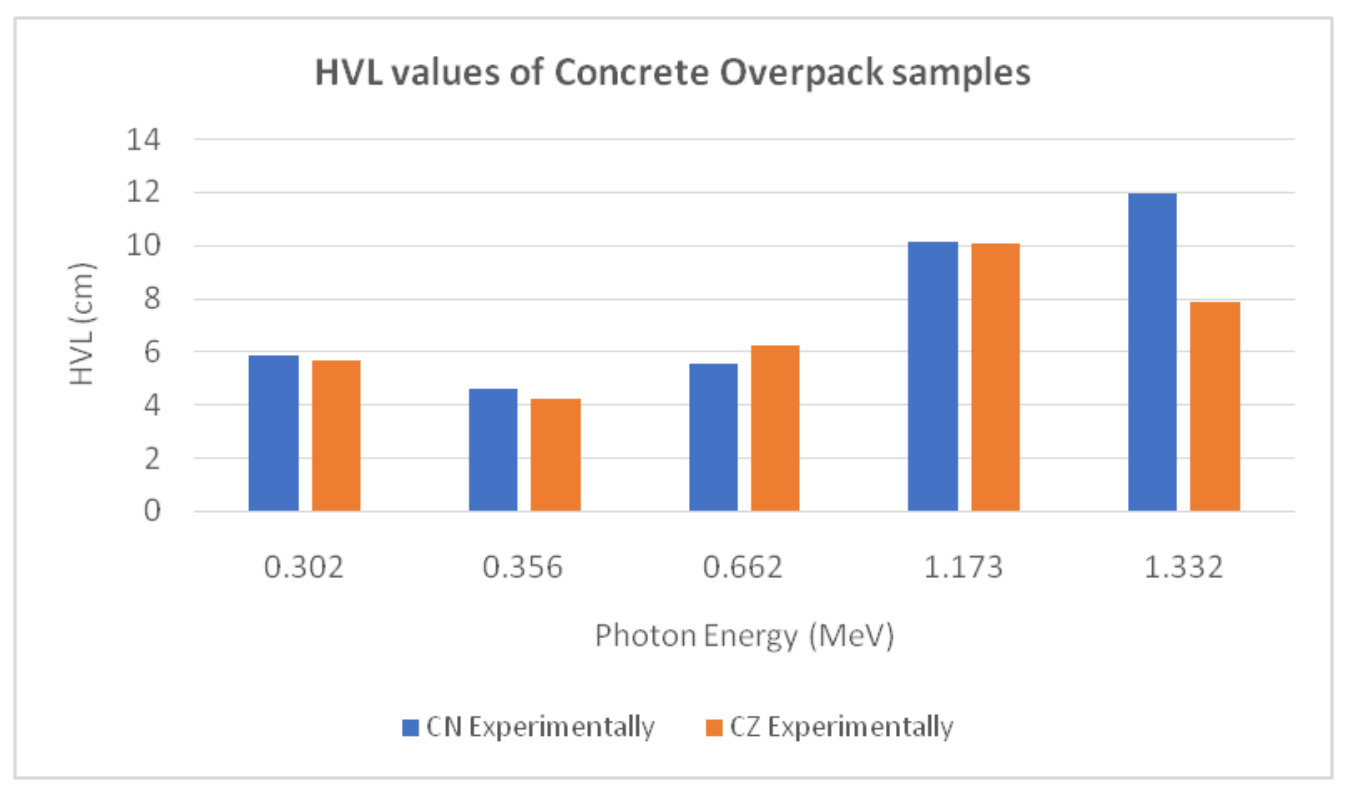

Figure 11: Variation of the Measured Half-Value Layer (HVL) vs. Photon Energy for the Concrete Overpack Samples.

\section{CONCLUSIONS}

The shielding properties of 316 stainless steel multi-layered spent fuel drycask are investigated experimentally and computationally using gamma-ray sources in which the concept of the cask consists of an inner 316 stainless steel canister coated with multi-layer ceramic oxide materials then surrounded with an outer shielding layer of concrete overpack. For the coated 316 stainless steel samples, the highest linear attenuation coefficient is observed computationally at $0.302 \mathrm{MeV}$ for 316 stainless steel coated with $\mathrm{ZrO}_{2}+\mathrm{TiO}_{2}$ double layers while the lowest linear attenuation coefficient is observed experimentally at $1.332 \mathrm{MeV}$ for 316 stainless steel coated with $\mathrm{Al}_{2} \mathrm{O}_{3}$ single layer. The maximum HVL value is observed at $1.332 \mathrm{MeV}$ photon energy peak for 316 stainless steel coated with $\mathrm{Al}_{2} \mathrm{O}_{3}$ while the lowest $\mathrm{HVL}$ value is observed at $0.302 \mathrm{MeV}$ for 316 stainless steel coated with $\mathrm{TiO}_{2}$. For the concrete overpack samples, the highest measured attenuation occurs for $\mathrm{CZ}$ sample at $0.356 \mathrm{MeV}$ photon energy while the lowest measured attenuation occurs for $\mathrm{CN}$ sample at 1.332 $\mathrm{MeV}$. Moreover, the maximum measured value of $\mathrm{HVL}$ is at $1.332 \mathrm{MeV}$ photon energy peak for CN sample while the lowest value is observed at $0.356 \mathrm{MeV}$ for $\mathrm{CZ}$ sample due to its high attenuation coefficients. 


\section{ACKNOWLEDGMENTS}

Work supported by the Russell Family Foundation Grant for research on High Level Waste Packages and Dry Casks. The authors express their sincere thanks to Abigail Casey and Caroline Campbell for their work preparing the stainless steel coated samples under the advisory of Dr. Leigh Winfrey during their term at University of Florida, Gainesville, under the activity of a DOE NEUP contract DE-NE0000736 Project NEUP 13-5427. Concrete samples were casted by Grancrete (former company of Armakap Technologies). The authors also acknowledge the Department of Nuclear Engineering for providing research during educational activities in the nuclear engineering laboratories.

\section{REFERENCES}

1. Zeinab Y. Alsmadi, Mohamed Bourham. Shielding Properties of Alloy 709 Advanced Austenitic Stainless Steel as Candidate Canister Material in Spent Fuel Drycasks. International Journal of Physics and Research, vol. 10, Issue. 2, pp. 11-26 (2020).

2. D. R. Mcalister. Gamma Ray Attenuation Properties of Common Shielding Materials. PhD thesis, 1955.

3. El-Sayed A. Waly et al., Impact of specialty glass and concrete on gamma shielding in multi-layered PWR drycasks, Progress in Nuclear Energy, Volume 94, 2017, Pages 64-70.

4. Sean Kerrigan, Zeinab Alsmadi, Zainab Alnoamani, Daniel Moneghan and Mohamed Bourham. Simulation and Experiments of Multi-Layer Drycask Shielding Materials. Transactions $25^{\text {th }}$ SMiRT conference, Structural Materials in Reactor Technology 25, Charlotte, NC, vol. 5, pp. 3410, August 4-9 (2019).

5. Samah Radwan, Leigh Winfrey and Mohamed Bourham. Simulation of Particle Impact on Protective Coating of High-Level Waste Storage Packages. Progress in Nuclear Energy, vol. 81, pp. 196-202, May 2015.

6. Michael A. Fusco, Leigh Winfrey and Mohamed A. Bourham. Shielding Properties of Protective Thin Film coatings and Blended Concrete Compositions for High Level Waste Storage Packages. Annals of Nuclear Energy, vol. 89, pp. 63-69, March 2016

7. Zeinab Y. Alsmadi, K.L. Murty. Effect of Strain Range on High Temperature Creep-Fatigue Behavior of Fe-25Ni-20Cr (wt.\%) Austenitic Stainless Steel (Alloy 709). Materials at High Temperatures (2020). DOI: 10.1080/09603409.2020.1859310.

8. Zeinab Y. Alsmadi, Abdullah Alomari, N. Kumar, K.L. Murty. Effect of Hold Time on High Temperature Creep-Fatigue Behavior of Fe-25Ni-20Cr (wt.\%) Austenitic Stainless Steel (Alloy 709). Material Science and Engineering: A, vol. 771, pp. 138591 (2020).

9. Zeinab Y. Alsmadi, K.L. Murty. High-temperature effects on creep-fatigue interaction of the Alloy 709 austenitic stainless steel. International Journal of Fatigue, vol. 143, 105987 (2021).

10. Al-Buriahi, M.S., et al. Investigation of barium borate glasses for radiation shielding applications. Appl. Phys. A 126, 68 (2020).

11. M.I. Sayyed, et al. Borate multicomponent of bismuth rich glasses for gamma radiation shielding application, Radiation Physics and Chemistry, Volume 161, 2019, Pages 77-82.

12. M.S. Al-Buriahi, et al. Structure, optical, gamma-ray and neutron shielding properties of $\mathrm{NiO}$ doped $\mathrm{B}_{2} \mathrm{O}_{3}-\mathrm{BaCO}_{3}-\mathrm{Li}_{2} \mathrm{O}_{3}$ glass systems. Ceramics Int. 46, 1711-1721 (2020).

13. El-Sayed A. Waly, Mohamed A. Bourham. Comparative study of different concrete composition as gamma-ray shielding materials. Annals of Nuclear Energy, Volume 85, 2015, Pages 306-310. 
14. Kaur, Updesh, et al. Comparative studies of different concretes on the basis of some photon interaction parameters. United Kingdom: N. p., 2012.

15. Singh, T., et al. (2009). Chemical composition dependence of exposure buildup factors for some polymers. Ann. Nucl. Energy $36,114-120$.

16. Harry Spilker, Martin Peehs, Hans-Peter Dyck, Guenter Kaspar and Klaus Nissen. Spent L WR Fuel Dry Storage in Large Transport and Storage Casks after Extended Burnup. J. Nuclear Materials, vol. 250, pp.63-74 (1997)

17. Toshiari Saegusa, Genki Yagawa and Masanori Aritomi. Topics of Research and Development on Concrete Cask Storage of Spent Nuclear Fuel. Nuclear Engineering and Design, vol. 238, pp.1168-1174 (2008)

18. Kwon, Se-Hun, et al. Plasma-Enhanced Atomic Layer Deposition of Ru-TiN Thin Films for Copper Diffusion Barrier Metals. Journal of The Electrochemical Society, vol. 153, no. 6, 2006, doi:10.1149/1.2193335.

19. Shan, C.x., et al. Corrosion Resistance of TiO2 Films Grown on Stainless Steel by Atomic Layer Deposition. Surface and Coatings Technology, vol. 202, no. 11, 2008, pp. 2399-2402., doi: 10.1016/j.surfcoat.2007.08.066.

20. Singh, H., et al. An Investigation of Material and Tribological Properties of Sb2O3/Au-Doped MoS2 Solid Lubricant Films under Sliding and Rolling Contact in Different Environments. Surface and Coatings Technology, vol. 284, 2015, pp. 281-289., doi: 10.1016/j.surfcoat.2015.05.049.

21. MicroShield, Grove Software, http://radiationsoftware.com/microshield/. 
